\title{
ANÁLISE DAS CONDIÇÕES HIGIENICOSSANITÁRIAS DE FOOD TRUCKS NO MUNICÍPIO DE SÃO PAULO
}

\section{ANALYSIS OF HYGIENIC AND SANITARY CONDITIONS OF FOOD TRUCKS IN THE CITY OF SÃO PAULO}

\author{
Rita de Cassia de Souza Fernandes ${ }^{1}$ \\ Marina de Almeida Lima ${ }^{2}$ \\ Elizabeth Maria Coppola Campos ${ }^{3}$ \\ Amanda Cardoso de Almeida Salvador ${ }^{4}$ \\ Bruna Dias Braga ${ }^{5}$ \\ Nadyne Porto de Souza ${ }^{6}$ \\ Daniela Maria Alves Chaud ${ }^{7}$ \\ Edeli Simioni de Abreu $^{8}$
}

Resumo: Devido ao aumento do hábito da alimentação fora do domicílio, os food trucks, um americanismo, fizeram sucesso no Brasil por oferecerem praticidade e agilidade. Para a garantia de um alimento seguro, que evite surtos de doenças transmitidas por alimentos, é essencial verificar se os estabelecimentos estão de acordo com a legislação municipal vigente. O objetivo do estudo foi analisar as condições higienicossanitárias de food trucks no município de São Paulo. Foram analisados 11 estabelecimentos, em seu horário de funcionamento. Para a coleta de dados, utilizou-se um check-list adaptado e os resultados comparados com a portaria municipal $n$ 을 2619/11. Os itens que mais apresentaram não conformidade foram: vestimenta; higienização dos reservatórios de água; pré-preparo dos alimentos; acondicionamento e transporte; presença de barreiras físicas entre as diferentes bancadas de trabalho; organização e armazenamento de utensílios; controle de pragas e ausência de Procedimentos Operacionais Padronizados. Uma particularidade encontrada refere que, pelo alimento só ser finalizado sob demanda do consumidor, 72,9\% dos estabelecimentos não tinham a necessidade de armazená-lo sob condições de temperatura e tempo adequadas. Por se localizarem em locais abertos, os food trucks estão vulneráveis à presença de microrganismos e poluentes. Concluiu-se que a análise das condições higienicossanitárias dos food trucks revelou-se insatisfatória, devendo haver uma adequação quanto às normas já preconizadas pela Portaria 2619/11, bem como maior atenção nos veículos e nas cozinhas de apoio.

Palavras-chave: Food trucks; condições higienicossanitárias; doenças transmitidas por alimentos.

\footnotetext{
1 Acadêmica do Curso de Graduação em Nutrição, Universidade Presbiteriana Mackenzie, Brasil. E-mail: ritadecsfernandes@gmail.com.

2 Acadêmica do Curso de Graduação em Nutrição, Universidade Presbiteriana Mackenzie, Brasil. E-mail: marinaalima2008@hotmail.com.

3 Acadêmica do Curso de Graduação em Nutrição, Universidade Presbiteriana Mackenzie, Brasil. E-mail: beth_coppola@hotmail.com.

4 Acadêmica do Curso de Graduação em Nutrição, Universidade Presbiteriana Mackenzie, Brasil. E-mail: a_mandinha66@hotmail.com.

$5^{-}$Acadêmica do Curso de Graduação em Nutrição, Universidade Presbiteriana Mackenzie, Brasil. E-mail: bru_bru_braga@hotmail.com.

6 Acadêmica do Curso de Graduação em Nutrição, Universidade Presbiteriana Mackenzie, Brasil. E-mail: nadyne.porto@hotmail.com.

7 Nutricionista, Mestre e Doutora em Ciências Aplicadas à Pediatria, Universidade Presbiteriana Mackenzie, Brasil. E-mail: daniela.chaud@mackenzie.br.

8 Nutricionista, mestre e doutora em Saúde Pública, Universidade de São Paulo, Brasil. E-mail: edelisabreu@gmail.com.

Revista Univap - revista.univap.br

São José dos Campos-SP-Brasil, v. 24, n. 46, dez. 2018. ISSN 2237-1753
} 
Abstract: Due to the increase in street feeding, the food trucks, a North American style, were successful in Brazil for offering practicality and agility. To assure safe foods that avoid foodborne disease outbreaks, it is essential to verify if the shops are according to the applicable municipal law. Thus, the aim of this study was to analyze the hygienic and sanitary conditions of food trucks in the city of São Paulo. 11 shops were analyzed in their business hours. For data gathering, an adapted checklist was used and the results were compared with the municipal ordinance No. 2619/11. The items that most presented non-conformity were: vestment; cleaning of water reservoirs; pre-preparation of foods; stowage and transport; presence of physical barriers between the different worktops; tidiness and storage of utensils; pest control and the absence of Standard Operational Procedures. A peculiarity found states that, because the food is finalized on consumer demand, $72.9 \%$ of the shops did not have the need of storing it under adequate conditions of temperature and time. Since they are located in open places, food trucks are vulnerable to the presence of microorganisms and pollutants. The conclusion drawn is that the analysis of the hygienic and sanitary conditions of the food trucks was proved unsatisfactory and there must be an adequacy according to the already recommended rules of the municipal ordinance No. 2619/11, as well as more attention to the vehicles and support kitchens.

Keywords: Food trucks; hygienic and sanitary conditions; foodborne diseases.

\section{INTRODUÇÂO}

Em virtude das intensas mudanças sociais, ocorridas nas últimas décadas, que afetaram o estilo de vida da população, como o desenvolvimento industrial e a participação da mulher no mercado de trabalho, tem-se verificado um aumento significativo da alimentação fora do domicílio (HENRIQUES et al., 2014; AKUTSU et al., 2005). Segundo dados da Pesquisa de Orçamentos Familiares 2008-2009 (IBGE, 2010), devido, principalmente, a essa escassez de tempo para preparo e consumo de alimentos, $33,1 \%$ dos gastos totais com alimentação pelos brasileiros são destinados para esse fim. Por ser uma opção viável para o modo de vida contemporâneo, esse mercado atende cerca de 2,5 bilhões de pessoas, em todo o mundo, diariamente, (CARDOSO; SANTOS; SILVA, 2009).

Foi nesse cenário promissor que, apesar de já existirem, durante a crise da economia americana, em 2008, chefes de cozinha famosos inovaram ao adotar uma nova estratégia de venda, os food trucks, restaurantes itinerantes montados em veículos automotores adaptados para o serviço, preparo e venda de alimentos, que, por possuírem custos operacionais inferiores, tornaram-se referência mundial e conquistaram parte significativa dos consumidores (ROOS et al., 2015; BOANOVA, 2014). No Brasil, fizeram sucesso, em relação aos demais restaurantes de refeições rápidas, por se destacarem quanto à qualidade, valor e velocidade, além de serem responsáveis pela popularização de comidas gourmet (INTUIT, 2012 apud ROOS et al., 2015). Entretanto, é essencial que tais refeições aliem a praticidade à agilidade para garantir aos consumidores, além de sabor, aroma, aparência e textura agradáveis, uma alimentação econômica e segura (BUSATO; GRÄF; ZAGONEL, 2014; CARDOSO; ARAÚJO, 2001).

De tal forma, há a necessidade de que orientações de higiene e normas técnicas de preparo e conservação sejam seguidas, pois durante a produção, processamento e 
consumo desses alimentos, possíveis contaminações químicas, físicas e biológicas em decorrência de práticas inadequadas, aumentam substancialmente o risco de ocorrência de Doenças Transmitidas por Alimentos (DTAs). (BUSATO; GRÄF; ZAGONEL, 2014; PRAXEDES, 2013).

Assim, para proteger e evitar a ingestão de alimentos contaminados pelo consumidor, mecanismos na área de vigilância sanitária foram criados pelos governos. Nesse cenário, destaca-se a legislação de alimentos, sendo, no município de São Paulo, utilizada a Portaria 2619 que preconiza que os estabelecimentos que realizam importação, exportação, extração, produção, manipulação, beneficiamento, acondicionamento, transporte, armazenamento, distribuição, embalagem e reembalagem, fracionamento ou comercialização e uso de alimentos, devem cumprir as leis federais, estaduais e municipais, bem como o Manual de Boas Práticas (MBP) e os Procedimentos Operacionais Padronizados (POPs), pré-estabelecidos na portaria (SEBRAE, 2015; BRANDALIZE, PERES, PASSONI, 2013). Além disso, institui a necessidade de que um profissional legalmente habilitado seja responsável técnico desse estabelecimento, garantindo, assim, a qualidade e segurança do produto perante os órgãos de vigilância em saúde (SÃO PAULO, 2011).

Atualmente, porém, não há parecer específico sobre o controle de qualidade das condições higienicossanitárias para comidas de rua, dentre elas para o setor de food trucks, e tanto empreendedores quanto órgãos responsáveis que realizam a inspeção no equipamento antes do seu efetivo funcionamento para fornecer sua permissão e instalação, vêm encontrando dificuldades, em termos de legislação e vigilância sanitária, visto que há características específicas nos food trucks que se diferenciam de restaurantes que possuem estrutura física fixa (BRASIL, 2014).

Além de da preocupação quanto ao pré-preparo dos alimentos que deve ser feito em uma cozinha industrial autorizada, é importante ressaltar que o armazenamento, transporte, manipulação, finalização e venda dos pratos nos próprios food trucks também podem causar alterações por meio de microrganismos deteriorantes e patogênicos presentes nos alimentos (ROOS et al., 2015). Considerando que todos os alimentos já se apresentam naturalmente contaminados, a grande preocupação é impedir que eles sobrevivam, multipliquem-se e que outros tipos sejam acrescentados às matérias-primas, como consequência de contaminação ambiental ou por manipulação inadequada (GERMANO et al, 2000).

É válido ressaltar que, nesses veículos, vários são os fatores que dificultam o controle e a garantia de segurança dos produtos oferecidos, como layout da cozinha móvel mal estruturado, que pode levar a uma contaminação cruzada, grande variedade de pratos e alimentos elaborados, possível presença de insetos e animais e impróprias práticas de manipulação de alimentos devido a carências de cursos de qualificação na área (CARDOSO; SOUZA; SANTOS, 2005; VARGAS; UENO, 2014). Busato, Gräf e Zagonel (2014) citam, também, a ausência de água potável ou garantia de sua 
qualidade, que pode levar a uma baixa frequência de lavagem de mãos e contaminação biológica dos alimentos; ausência de áreas de descarte para lixo, de sanitários públicos, e, para controle de tempo e temperatura, de termômetros calibrados e refrigeração dos alimentos. Nesse cenário, a possibilidade da contaminação por material particulado presente no ar também é considerada por Roncancio, Quicazán e Cárdenas (2015), pois pode gerar danos à saúde devido à proximidade de áreas de tráfego de veículos.

O objetivo deste trabalho foi analisar as condições higienicossanitárias de food trucks no município de São Paulo, como também as diferentes etapas de produção, armazenamento, transporte, manipulação e venda de alimentos em food trucks, assim como o destino dos resíduos gerados, comparando-as com restaurantes que possuem estrutura física fixa e de comércio ambulante de alimentos, de modo a verificar se, em relação à legislação higienicossanitária municipal vigente, se as condições higienicossanitárias garantem a qualidade e segurança do alimento vendido, prevenindo os surtos de DTAs.

\section{METODOLOGIA}

O estudo foi observacional descritivo de delineamento transversal, realizado a partir de coleta de dados primários, realizado em food trucks localizados na região central do município de São Paulo e utilizou-se a amostragem por conveniência. Os dados foram colhidos no início do mês de abril de 2016. Cada food truck foi observado por, aproximadamente, uma hora, durante seu horário de funcionamento. O estudo compreendeu o período de fevereiro a maio de 2016.

Como instrumento de coleta de dados, foi aplicado um check-list adaptado da metodologia de Souza et al. (2015) e de dados da Portaria 2619 (SÃO PAULO, 2011), para a análise das condições higienicossanitárias das diferentes etapas de produção, armazenamento, transporte, manipulação e venda de alimentos nos food trucks, bem como os resíduos gerados. As opções de respostas foram "SIM", quando o estabelecimento atendeu ao item observado; "NÃO", quando se apresentou em desconformidade ao item observado; "NÃO SE APLICA", quando os itens avaliados não se aplicaram ao food truck, e "NÃO OBSERVADO", quando, no momento da coleta de dados, não foi possível avaliar a aplicabilidade de determinados itens, seja pela impossibilidade de avaliação ou de o item não ser relatado pelos funcionários.

Para a organização dos dados e a tabulação das informações coletadas, foi utilizado o programa Microsoft Excel versão 2013 e os dados analisados por meio da estatística descritiva e, em relação ao uso dos POPs e sua aplicação no controle efetivo de pragas, foi utilizada a correlação de Pearson. O nível de significância considerado foi de $p<0,05$. Após a coleta de dados, realizada pelo preenchimento do questionário pelos pesquisadores, os resultados foram avaliados segundo o percentual de itens que se apresentam em conformidade com a legislação vigente e comparados com estudos 
recentes que também avaliaram as condições higienicossanitárias de restaurantes fixos e de comércio ambulante de alimentos.

Foram devidamente explicados aos donos ou responsáveis pelos estabelecimentos os objetivos e procedimentos do estudo e os riscos, mesmo que mínimos. Ao consentirem, voluntariamente, em participar do estudo, assinaram o termo de consentimento livre e esclarecido (TCLE). No banco de dados da pesquisa principal, foram mantidos o anonimato e a confidencialidade dos dados. Este projeto foi aprovado pelo Comitê de Ética em Pesquisa sob o número CAAE - 48483015.7.0000.0084.

\section{RESULTADOS E DISCUSSÃO}

A amostra foi composta por 11 food trucks, localizados em três food parks da região central do município de São Paulo.

\subsection{Higiene pessoal, estado de saúde e programa de capacitação}

Conforme se observa na Tabela 1, há um grande percentual de itens não conformes, no que se refere à vestimenta, sendo utilizados uniformes e sapatos não adequados à atividade de cozinha, uso de adornos e ausência de boa apresentação pessoal dos funcionários e manipuladores, embora, em relação à higiene pessoal e estado de saúde, alguns requisitos tenham sido atendidos, como manter as mãos limpas e unhas curtas, realizar exames de rotina e se proteger, em caso de ferimento, sendo utilizados curativos por $60 \%$ dos entrevistados, e luvas por $20 \%$.

Tabela 1 - Higiene pessoal, estado de saúde e programa de capacitação de funcionários de food trucks da região central do munícipio de São Paulo, 2016.

\begin{tabular}{|c|c|c|c|c|}
\hline & $\begin{array}{c}\text { Conforme } \\
(\%)\end{array}$ & $\begin{array}{c}\text { Não } \\
\text { conforme (\%) }\end{array}$ & $\begin{array}{l}\text { N.A.* } \\
(\%)\end{array}$ & $\begin{array}{c}\text { N.O** } \\
(\%)\end{array}$ \\
\hline Uso de uniformes & - & 100 & - & - \\
\hline Uso de calçados fechados e antiderrapantes & 18,2 & 81,8 & - & - \\
\hline Uso de adornos & 45,5 & 54,5 & - & - \\
\hline Boa apresentação pessoal & 36,4 & 63,6 & - & - \\
\hline $\begin{array}{l}\text { Mãos limpas, unhas curtas, sem base e } \\
\text { esmalte }\end{array}$ & 72,7 & 18,2 & - & 9,1 \\
\hline Cabelos presos & 54,5 & - & 45,5 & - \\
\hline Cabelos protegidos com touca ou rede & 45,5 & 54,5 & - & - \\
\hline $\begin{array}{l}\text { Uso de pegadores ou luvas para evitar } \\
\text { contato das mãos com alimentos prontos } \\
\text { para consumo }\end{array}$ & 27,3 & 54,5 & 9,1 & 9,1 \\
\hline $\begin{array}{l}\text { Exames de rotina (sangue, fezes, urina) são } \\
\text { realizados semestralmente }\end{array}$ & 72,7 & 27,3 & - & - \\
\hline $\begin{array}{l}\text { Funcionários não trabalham quando ficam } \\
\text { doentes }\end{array}$ & 54,5 & 45,5 & - & - \\
\hline $\begin{array}{l}\text { Em caso de ferimento, há cuidado e } \\
\text { proteção adequado do local ferido }\end{array}$ & 90,9 & 9,1 & - & - \\
\hline
\end{tabular}




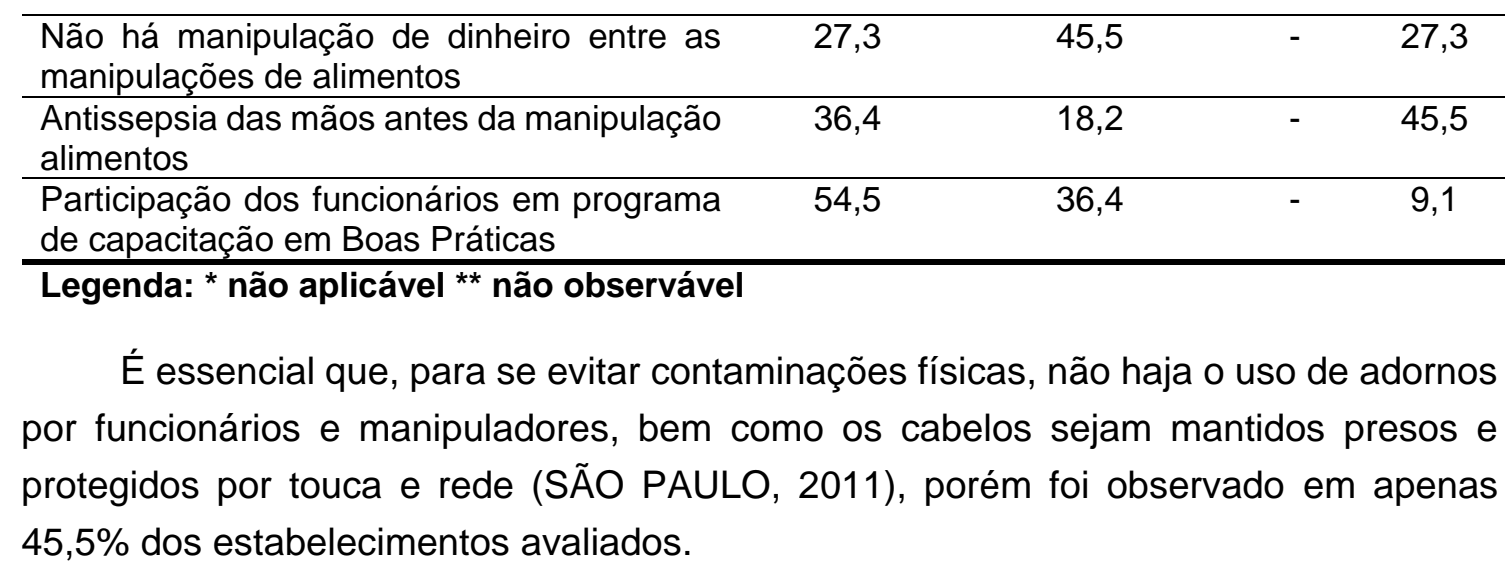

Após a finalização do alimento, apenas $27,3 \%$ dos food trucks evitavam o contato manual por meio do uso de pegadores ou luvas, o que pode levar à contaminação biológica, visto que apenas $36,4 \%$ realizam a antissepsia das mãos corretamente antes da manipulação. Também se verificou que, devido ao número reduzido de funcionários, $45,5 \%$ dos manipuladores de alimentos também eram responsáveis por receber os pagamentos dos clientes, manuseando dinheiro, fonte potencial de contaminação (OLIVEIRA; MAITAN, 2010).

Notou-se que não há a preocupação, pelos proprietários dos food trucks analisados, quanto ao local para os funcionários realizarem suas necessidades fisiológicas, visto que $81,1 \%$ utilizam banheiros químicos, e $18,2 \%$ o sanitário que o food park cede aos frequentadores.

Apesar de ser essencial para se prevenir a contaminação dos alimentos que os funcionários recebam orientações de higiene e boas práticas de manipulação, aliado a treinamento, visto que são um dos principais responsáveis pela contaminação dos alimentos, tornando-se um possível transmissor de DTAs, apenas 54,5\% dos estabelecimentos aderem a essa prática, sendo que 36,4\% possuem certificados de cursos da ANVISA e 18,4\%, de cursos técnicos (AKUTSU et al., 2005; GERMANO et al., 2000).

\section{2 Água utilizada}

Todos os food trucks analisados possuíam volume de água potável compatível com a atividade realizada. Porém, de acordo com a Tabela 2, 18,2\% não dispunham de reservatório de água fixo e de fácil acesso, utilizando-se, em muitos casos, galões adquiridos pelos estabelecimentos. Em relação à higienização, apenas 27,3\% afirmaram realizar a cada seis meses, conforme recomenda a Portaria 2619 (SÃO PAULO, 2011), e somente $18,2 \%$ contratam uma empresa terceirizada para esse fim, resultado semelhante ao encontrado nos estudos de Cardoso, Souza e Santos (2005). 
Tabela 2 - Água utilizada em food trucks da região central do município de São Paulo, 2016.

\begin{tabular}{|c|c|c|c|c|}
\hline & $\begin{array}{l}\text { Conforme } \\
(\%)\end{array}$ & $\begin{array}{c}\text { Não } \\
\text { conforme (\%) }\end{array}$ & $\begin{array}{l}\text { N.A.* } \\
(\%)\end{array}$ & $\begin{array}{l}\text { N.O.* } \\
(\%)\end{array}$ \\
\hline Reservatório de água é fixo e de fácil acesso & 72,7 & 18,2 & 9,1 & - \\
\hline Reservatório é higienizado a cada seis meses & 27,3 & 36,4 & 9,1 & 27,3 \\
\hline $\begin{array}{l}\text { A higienização é feita com empresa } \\
\text { terceirizada }\end{array}$ & 18,2 & 45,5 & 9,1 & 27,3 \\
\hline $\begin{array}{l}\text { Terceirizada emite certificado após } \\
\text { higienização }\end{array}$ & 9,1 & 45,5 & 9,1 & 36,4 \\
\hline
\end{tabular}

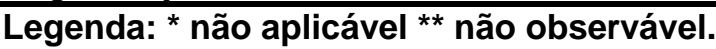

Portanto, observa-se que, apesar de ser utilizada água potável, a higienização do reservatório não é feita periodicamente e muito menos com empresas capacitadas para realizar o serviço. Visto que a água pode transmitir patógenos e, além de ser utilizada na produção e higienização de móveis e utensílios, também é utilizada na antissepsia das mãos, é essencial que se atenda, efetivamente, a esse item, para garantir a segurança microbiológica dos alimentos oferecidos pelo estabelecimento (SÃO PAULO, 2011).

\subsection{Pré-preparo dos alimentos}

Dos food trucks analisados, 54,5\% realizam o pré-preparo dos alimentos na residência dos donos, resultados semelhantes aos encontrados em comércio ambulantes de alimentos, no estudo de Vargas e Ueno (2014), sendo que somente $36,4 \%$ realizam em cozinha de apoio que possui alvará sanitário. Destes, apenas metade possui responsável técnico.

Visto que os food trucks são estabelecimentos que realizam atividades de produção, manipulação e venda de alimentos, torna-se, de acordo com a Portaria 2619, obrigatória a presença de um responsável técnico, legalmente habilitado, na cozinha de apoio (SÃO PAULO, 2011). Dentre suas inúmeras funções, o responsável técnico é o profissional capacitado para elaborar, implantar, implementar e monitorar a capacitação de funcionários, além do MBP e dos POPs. Akutsu et al (2005), após analisar 40 unidades produtoras de refeições (UPRs) e 10 UANs, identificaram que houve maior percentual de atendimento aos itens considerados imprescindíveis para as boas práticas de manipulação e produção naqueles que possuíam responsáveis técnicos.

De tal forma, observa-se que, independentemente de qual tipo de estabelecimento, se houver oferecimento de serviços de alimentação, é necessário um responsável técnico para uma melhor adequação e orientação de higiene e normas técnicas de preparo, bem como outros itens, visto que a cozinha de apoio deve estar em conformidade com as legislações vigentes para que as condições 
higienicossanitárias dos alimentos garantam a segurança dos alimentos, que apenas serão finalizados nos food trucks (BUSATO; GRÄF; ZAGONEL, 2014).

\subsection{Transporte de alimentos}

Os resultados encontrados são preocupantes no tocante à qualidade higienicossanitária, visto que $54,5 \%$ dos food trucks não acondicionam corretamente o alimento pré-preparado e não o mantém em condições de tempo e temperatura adequadas durante o transporte da cozinha de apoio ao food truck, o que pode levar ao risco de contaminação cruzada e da multiplicação de patógenos, bem como à deterioração do alimento (SACCOL, 2007). Além disso, são utilizados, como meios de transporte, carros de passeio ou peruas, inapropriados para essa finalidade, visto que, além da obrigatoriedade destes em estarem em bom estado de conservação, é proibido o transporte de pessoas junto com alimentos (SÃO PAULO, 2011), o que no ritmo frenético das grandes cidades, pode vir a ocorrer com frequência, porém se reconhece tal item como difícil de ser avaliado. Devido à inexistência de um transporte adequado, e visto que apenas $9,1 \%$ realizam o monitoramento da temperatura do alimento durante as etapas de transporte, $63,6 \%$ dos responsáveis relataram utilizar equipamentos para evitar que o alimento transportado seja contaminado, tentando garantir condições adequadas de temperatura. Dentre os referidos, destacou-se o uso de caixas térmicas $(71,4 \%)$, resultado semelhante ao encontrado no estudo de Agostinho (2013), no qual $75,1 \%$ dos entrevistados realizam o transporte dos alimentos com o mesmo equipamento.

É válido ressaltar a importância da verificação sistemática da temperatura dos alimentos pré-preparados que serão transportados até os food trucks para a finalização por meio da aplicação de uma sequência de inspeções e medições, verificando as temperaturas no transporte de alimentos refrigerados e congelados, para que, assim, se garanta a qualidade higienicossanitária (ABREU, SPINELLI, SOUZA PINTO, 2016).

\subsection{Estrutura física}

Uma das particularidades dos food trucks refere-se à sua estrutura física. Observou-se que $73 \%$ dos food trucks não apresentavam barreiras físicas entre as diferentes bancadas de trabalho, principalmente no que se refere ao preparo do alimento. Também não foi encontrado um fluxo de produção ordenado e sem cruzamentos, resultados estes preocupantes. De acordo com o que é descrito pelo Codex Alimentarius (1993), há a necessidade dos estabelecimentos serem projetados de maneira a permitir a separação, por meio de divisões, entre os diferentes tipos de operações que possam levar às contaminações cruzadas, que é considerada uma das principais causas da ocorrência de DTAs (POERNER et al, 2009). Assim, alguns fatores, 
como a presença de barreiras físicas também devem estar presentes para atender aos requisitos relacionados à qualidade dos alimentos, principalmente entre a finalização do alimento e o público que aguarda o pedido, estando em conformidade apenas por $54 \%$ dos estabelecimentos.

Em relação à iluminação artificial dos veículos, apesar de grande parte do dia os food trucks se utilizarem de fonte de luz natural, $72,7 \%$ atenderam ao que preconiza a Portaria 2619 (SÃO PAULO, 2011), sendo uniformes, sem sombras ou cantos escuros e estar protegidas contra quebras, garantindo assim uma boa prática de manipulação de alimentos. Quanto aos caixas de pagamento, 63,3\% localizam-se na entrada dos veículos analisados.

Outro fator importante para os alimentos vendidos na rua refere-se à localização, que possui extrema relevância quanto à contaminação de alimentos, visto que fatores como: poluição, presença de vetores e grande circulação de pessoas no local de comércios alimentícios apresentam vulnerabilidade. Por se tratar de uma cidade como São Paulo, em que os comerciantes buscam por um ponto com grande fluxo de pessoas, como avenidas, visando a uma maior comercialização, a localização constitui um fator de risco que pode comprometer a segurança dos alimentos. Assim, no presente estudo, $81,1 \%$ dos food trucks estão localizados em local com poeira e fumaça de veículos, resultado semelhante ao de Franco e Ueno (2010), que apresentou 75,9\% de não conformidades. Nenhum dos veículos analisados encontrava-se próximo a esgotos mal vedados e bueiros entupidos.

\subsection{Armazenamento}

O controle de temperatura é uma etapa de crucial importância para o processo de armazenamento atender às normas reguladoras. Neste contexto, evidencia-se a importância do controle da temperatura de armazenamento na conservação de alimentos, para minimização de crescimento de microrganismos patogênicos, oferecendo, assim, riscos à saúde do consumidor (TORASSI, 2009).

De acordo com o que se observa na Tabela 3, muitos dos itens observados não puderam ser avaliados, visto que a análise observacional compreendeu o período do almoço, ao qual as pesquisadoras não foram autorizadas a entrar em alguns veículos, o que quantifica certa limitação do presente estudo, principalmente no que se refere à temperatura de alimentos pré-preparados que devem ser resfriados de $60^{\circ} \mathrm{C}$ para $10^{\circ} \mathrm{C}$, em até 2 horas, visto que não houve o acesso à cozinha de apoio, em 63,6\% dos food trucks, e cujas informações os funcionários e manipuladores não souberam relatar. Porém, tal conduta é essencial para a redução na faixa de risco de crescimento de patógenos (AMORIM, 1999). 
Em relação à manutenção da temperatura de alimentos quentes, uma particularidade presente nos food trucks refere ao fato de que, nos veículos, os alimentos são finalizados e entregues diretamente para o consumidor, não necessitando, em sua maioria, armazenamento em estufas ou equipamentos apropriados. Porém, dos estabelecimentos cujo item se aplicava, todos mantiveram os alimentos a uma temperatura acima de $60^{\circ} \mathrm{C}$ até o momento de serem servidos, diferentemente do estudo de Amorim (1999), no qual apenas metade dos estabelecimentos analisados mantinha a temperatura de conservação correta.

\section{Tabela 3 - Armazenamento de alimentos comercializados em food trucks da} região central do município de São Paulo, 2016

\begin{tabular}{|c|c|c|c|c|}
\hline $\begin{array}{l}\text { Manutenção dos alimentos resfriados e } \\
\text { quentes }\end{array}$ & $\begin{array}{l}\text { Conforme } \\
(\%)\end{array}$ & $\begin{array}{l}\text { Não } \\
\text { conforme } \\
(\%)\end{array}$ & $\begin{array}{l}\text { N.A. }^{*} \\
(\%)\end{array}$ & N.O**(\%) \\
\hline $\begin{array}{l}\text { Monitoramento da temperatura é feito com } \\
\text { registro em planilha (por amostragem) } \\
\text { Alimentos quentes mantidos acima dos }\end{array}$ & 36,4 & 27,3 & 9,1 & 27,3 \\
\hline $\begin{array}{l}60^{\circ} \mathrm{C} \text {, por no máximo } 6 \text { horas } \\
\text { Alimentos resfriados } s \text { mantidos abaixo de }\end{array}$ & 27,3 & 0 & 45,5 & 27,3 \\
\hline $\begin{array}{l}5^{\circ} \mathrm{C} \\
\text { Os alimentos pré-preparados são } \\
\text { resfriados de } 60^{\circ} \mathrm{C} \text { para } 10^{\circ} \mathrm{C}(\mathrm{em} \text { até } 2\end{array}$ & 63,6 & 0 & 18,2 & 18,2 \\
\hline $\begin{array}{l}\text { horas), para serem armazenados e } \\
\text { finalizados posteriormente }\end{array}$ & 36,4 & 0 & 0 & 63,6 \\
\hline
\end{tabular}

Legenda: * não aplicável ** não observável.

No que se refere à refrigeração, espera-se que a temperatura esteja inferior a 5우 de tal forma, $63,6 \%$ dos food trucks estão em conformidade com tal item, o que não foi possível notar no estudo de Genta, Mauricio e Matioli (2005), que avaliou as boas práticas de restaurantes self-service da região central de Maringá. Assim, observa-se que a estrutura e forma de atuação do food truck não compromete as práticas adequadas, cabendo aos responsáveis do estabelecimento se atentarem quanto a esse tópico.

\subsection{Utensílios e equipamentos}

Foi observado que $27,3 \%$ dos food trucks não estavam em conformidade com o que preconiza a Portaria 2619 (SÃO PAULO, 2011), tanto no que diz respeito ao material dos utensílios quanto ao estado de conservação. O maior problema detectado refere-se à questão da organização e armazenamento dos utensílios, pois apenas $36,4 \%$ estavam adequados. Essa situação deve ser frequente devido ao espaço físico do food truck, que, por considerável limitação de espaço físico, pode dificultar o acondicionamento dos utensílios. Ainda assim, esse tópico precisa de mais atenção por parte dos proprietários, uma vez que têm o dever de manter a organização, para garantir, além da qualidade dos alimentos, a segurança dos funcionários. Por outro lado, 
na maior parte dos estabelecimentos $(63,6 \%)$, os utensílios estavam, aparentemente, em quantidade suficiente.

Para Silva Júnior (2007), as superfícies de contato com os alimentos podem ser classificadas como de alto risco ou baixo risco de causar DTAs. As de alto risco, presentes desde a recepção da matéria prima até sua distribuição, são, praticamente, observadas como totalidade nos food trucks. Por carregarem partículas de poeira e microrganismos, necessitam de serem lisas e íntegras, possibilitando fácil higienização. Tais características foram encontradas em $72,7 \%$ dos food trucks. Dos $18,1 \%$ em não conformidade, observou-se a presença de superfícies de madeira, material não recomendando por possuir reentrâncias, nas quais os microrganismos se acumulam, além de possuir difícil higienização (FREITAS et al., 2015; COSTA et al., 2013).

Em relação à existência de termômetros, é obrigatório que este esteja nos locais de produção, especialmente para controlar a temperatura dos locais de armazenamento e conservação (SÃO PAULO, 2011). Só foi possível observar a conformidade desse item em $36,4 \%$ dos veículos analisados. Adicionalmente ao controle de qualidade dos alimentos pelo binômio tempo e temperatura, 90,9\% possuem equipamentos de conservação pelo frio.

Dos food trucks em que era necessário o armazenamento de alimentos quentes, $75 \%$ possuíam equipamentos de conservação pelo calor nos veículos. Nesse sentido, os restaurantes fixos se diferenciam, principalmente os de self-service, que devem dispor de balcões térmicos com temperatura entre $80^{\circ} \mathrm{C}$ e $90^{\circ} \mathrm{C}$ (SOARES; MONTEIRO; SCHAEFER, 2009). O controle da combinação tempo/temperatura torna-se fundamental para inibir a proliferação microbiana em alimentos que são preparados com antecedência (CARDOSO; SOUZA; SANTOS, 2005).

\subsection{Manipulação de alimentos}

Quando analisados se os molhos e temperos se encontram em sachês, apenas $40,0 \%$ dos food trucks estão em conformidade, enquanto que os demais utilizam bisnagas ou nas próprias embalagens de origem. Vale ressaltar que, apesar de ser importante do ponto de vista higienicossanitário e microbiológico disponibilizar os sachês aos consumidores, se utilizadas bisnagas, estas devem estar identificadas, respeitando o prazo de validade expresso no rótulo original, assim que o produto for aberto, e acondicionadas sob temperatura adequada (BRASIL, 2014). Quanto aos demais alimentos pré-preparados recebidos da cozinha de apoio, apenas $54,5 \%$ dos estabelecimentos os embalam adequadamente e identificam-no quanto à validade.

O uso do gelo não se aplicou em $72,7 \%$ dos food trucks analisados, sendo que os que utilizavam $(18,2 \%)$ se encontraram em total conformidade. De acordo com a Portaria 2619, a água utilizada para a produção de gelo deve seguir os padrões de 
potabilidade estabelecidos pela legislação vigente e estocada sob condições sanitárias adequadas (SÃO PAULO, 2011).

Em relação aos dois últimos tópicos, os cuidados também devem ser direcionados ao manipulador, cuja higienização das mãos é essencial para evitar uma possível contaminação biológica (PIRAGINE, 2005).

Observa-se, na Figura 1, uma especificidade positiva dos food trucks em relação aos restaurantes fixos, no que se refere ao armazenamento em temperaturas adequadas dos produtos finalizados e prontos para o consumo. Visto que os alimentos pré-preparados nas cozinhas de apoio apenas são finalizados sob demanda do consumidor, $72,9 \%$ dos food trucks não tinham a necessidade de armazená-los sob condições de temperatura e tempo adequadas, o que pode impedir a multiplicação de microrganismos devido às práticas inadequadas. Dos que preparavam com antecedência, devido ao grande fluxo de pedidos, todos estavam em conformidade.

\section{Figura 1 - Armazenamento em temperatura adequada de produtos finalizados de food trucks da região central do município de São Paulo, 2016.}

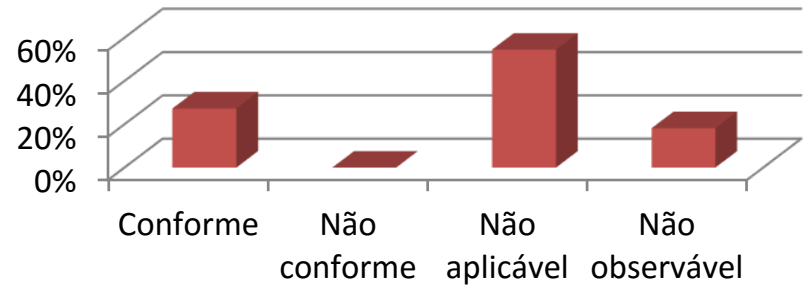

Fonte: Os autores (2016).

Portanto, a depender do tipo de alimento oferecido, não é necessário que os food trucks tenham suporte para armazenar os alimentos finalizados, diferentemente dos restaurantes fixos, como os de self-service, que necessitam de estrutura adequada para controlar a temperatura dos alimentos, principalmente os submetidos à cocção, que devem ser mantidos em temperaturas acima de $60^{\circ} \mathrm{C}$, por, no máximo, seis horas, evitando a multiplicação de microrganismos à temperatura ambiente (ZANDONADI et al, 2007; SÃO PAULO, 2011).

\subsection{Descarte de resíduos}

Conforme se observa na Tabela 4, a grande maioria dos food trucks está em conformidade quanto ao descarte apropriado de água de lavagem na pia e resíduos orgânicos e secos, bem como o uso de sacos plásticos nas lixeiras. Porém, 72,7\% não identificam as lixeiras quanto ao seu conteúdo, indo em discordância à Portaria 2619, visto que os recipientes devem estar identificados, disponíveis em número suficiente e 
possuírem capacidade compatível com a quantidade de resíduos gerados (SÃO PAULO, 2011).

Ressalta-se que, devido ao fato de os food trucks possuírem espaço reduzido e uma única entrada e saída para resíduos gerados e matérias primas, para evitar a contaminação cruzada e atração de vetores e pragas, estes devem ocorrer em horários diferentes, sendo o lixo levado a locais fechados e isolados da área de finalização do alimento que ocorre no veículo (PEREIRA, 2006; SÃO PAULO, 2011). Tal fato somente é observado em $27,3 \%$ dos food trucks, o que pode ser justificado pela falta de estrutura existente nos food parks aos quais estão localizados.

\section{Tabela 4 - Descarte de resíduos e equipamentos utilizados em food trucks da} região central do município de São Paulo, 2016.

\begin{tabular}{|c|c|c|c|c|}
\hline & $\begin{array}{c}\text { Conforme } \\
(\%)\end{array}$ & $\begin{array}{c}\text { Não } \\
\text { conforme (\%) }\end{array}$ & $\begin{array}{l}\text { N.A.* } \\
(\%)\end{array}$ & 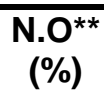 \\
\hline $\begin{array}{l}\text { A água de lavagem de pia fica armazenada e } \\
\text { é descartada após os trabalhos em local } \\
\text { próprio } \\
\text { Os resíduos orgânicos e secos são } \\
\text { armazenados em lixeiras sem } \\
\text { acondicionamento manual } \\
\text { As lixeiras são identificadas com o conteúdo } \\
\text { nelas existente } \\
\text { Os resíduos orgânicos e secos são } \\
\text { armazenados em lixeiras com sacos } \\
\text { plásticos } \\
\text { O local do food truckpossui espaço protegido } \\
\text { para alocar os sacos plásticos devidamente } \\
\text { fechados }\end{array}$ & 72,7 & 72,7 & 0 & 27,3 \\
\hline
\end{tabular}

Dos estabelecimentos que utilizam óleo para finalizar os alimentos, $60 \%$ não possuem local específico (bombonas) para o armazenamento e descarte adequado, sendo que apenas metade possui parceria com uma empresa ambiental licenciada, especializada na coleta ou reprocessamento, o que vai contra o que preconiza a Portaria 2619, que proíbe o lançamento de gorduras e óleos comestíveis utilizados no preparo de alimentos em encanamentos e no lixo.

\subsection{Controle de pragas}

A Portaria 2619 preconiza que as instalações internas e externas devem ser livres de indícios e vetores de pragas urbanas (SÃO PAULO, 2011). É inviável que food trucks se adequem completamente nessa lei por estarem localizados em um espaço aberto, não havendo forma de realizar um controle total efetivo de pragas. De acordo com a legislação, são necessárias não só medidas corretivas, como também medidas preventivas. Isso implica na adoção do uso de barreiras, por exemplo. A ausência de barreiras bloqueadoras, como telas, na instalação, permite o acesso de animais e 
sujidades, que favorecem a contaminação dos alimentos (NUNES, 2009). Quando questionados, $54,5 \%$ dos participantes disseram realizar o controle de pragas nos veículos que comportam os foods trucks. Porém houve casos em que esse controle é realizado pelos proprietários, e não por empresas capacitadas. A aplicação de inseticidas e raticidas domésticos pode configurar riscos de contaminação química ou mesmo de acidente de trabalho, em virtude da alta toxicidade e exigência de cuidados especiais para manuseio, estocagem e descarte (SBCTA, 1993 apud CARDOSO; SOUZA; SANTOS, 2005).

No caso daqueles em que o controle de pragas é realizado mediante a contratação de empresa especializada, foi possível observar que apenas $58,4 \%$ delas fornecem os documentos exigidos pela Portaria 2619, como relatório dos produtos utilizados, atividades feitas e alvarás (SÃO PAULO, 2011). Para serem realizadas, as medidas preventivas para o controle da infestação, as instalações e atividades desenvolvidas pelos food trucks devem ser consideradas.

\subsection{Documentação}

Conforme se observa na Figura 2, 72,7\% dos food trucks analisados possuíam Manual de Boas Práticas, sendo que apenas 45,5\% possuem os Procedimentos Operacionais Padronizados. Em relação a esse dado, é interessante notar que 62,5\% dos food trucks que possuem MPB não contém os POPs anexados ao manual, o que pode comprometer a qualidade e segurança do produto oferecido. Além disso, a inexistência dos documentos está em desacordo com o que preconiza a RDC 214, pois estes devem estar acessíveis aos funcionários para implementação das boas práticas de fabricação e disponíveis às autoridades (BRASIL, 2014).

\section{Figura 2 - Documentação de food trucks da região central do município de São} Paulo, 2016.

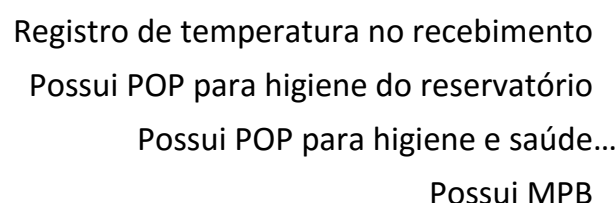

Possui MPB

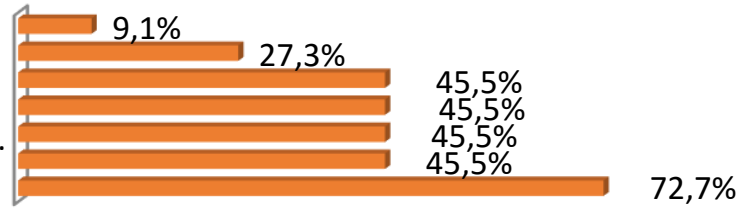

Percentual de conformidades

Fonte: Os autores (2016).

Em relação ao POP de controle integrado de vetores e pragas urbanas, foi encontrada uma correlação $(r=0,76)$, ou seja, grande maioria dos food trucks que o possuíam realizavam os procedimentos necessários para impedir a atração, o abrigo, o acesso e ou a proliferação de animais sinantrópicos dentro dos estabelecimentos. Em relação aos outros POPs analisados, não foram encontradas correlações significativas, 
sendo elas fracas ou muito fracas. Assim, constata-se que o objetivo proposto pela existência dos POPs foi alcançado, visto que serve como modelo básico de orientação dos profissionais, pois descreve, de forma simples e objetiva, as rotinas de serviços realizadas nos estabelecimentos, garantindo a eficácia do processo e a segurança dos alimentos (SÃO PAULO, 2011).

No que se refere à temperatura dos alimentos, observa-se que, assim como não há monitoramento da temperatura dos alimentos por nenhum food truck durante as etapas de transporte, apesar do uso de equipamentos para controlar a temperatura, apenas $9,1 \%$ afere o registro em planilhas da temperatura da mercadoria pré-preparada que é recebida nos food trucks para a finalização. Controlar o tempo que o alimento fica exposto a uma temperatura inadequada é essencial para a prevenção de DTAs, visto que microrganismos patogênicos tendem a se multiplicar (CARDOSO; SOUZA; SANTOS, 2005). Para garantir a segurança microbiológica dos alimentos, também é importante registrar em planilhas e monitorar a temperatura de geladeiras e freezers, 0 que só é feito por $27,1 \%$ dos food trucks analisados.

Dos estabelecimentos que preparavam alimentos fritos $(n=5)$, apenas $20 \%$ realizam o registro do reaquecimento do óleo, prática essencial para se evitar que o óleo ultrapasse $180^{\circ} \mathrm{C}$, devido à liberação de peróxidos e de acroleína, substância considerada tóxica (SÃO PAULO, 2011; MARQUES; VALENTE; ROSA, 2009).

\subsection{Considerações finais}

Após uma análise detalhada das diferentes etapas de produção de alimento nos food trucks, observou-se que, devido à sua importância social, nutricional, gastronômica e ao seu potencial mercadológico por se assemelhar aos restaurantes de comida rápida, aliando praticidade e agilidade, não cabendo, portanto, o armazenamento desse alimento, é necessária uma maior atenção quanto às condições higienicossanitárias oferecidas por esses estabelecimentos. Aliado a isso, por serem estabelecimentos que se localizam em locais abertos e recebem um fluxo frequente de pessoas, estão mais vulneráveis à presença de microrganismos e poluentes, torna-se essencial uma maior orientação e adequação das normas vigentes por parte dos órgãos competentes quanto às particularidades encontradas nos food trucks, que refletem uma carência de normas sanitárias específicas para controle e adequação das boas práticas de manipulação, para evitar DTAs.

Portanto, para garantir a segurança dos alimentos, evitando contaminação cruzada, é de essencial importância que as autoridades competentes fiscalizem a localização e os locais de pré-preparo e finalização dos alimentos, bem como que os responsáveis capacitem seus funcionários, os food parks ofereçam melhor infraestrutura para alocar os veículos, e que seja obrigatória a presença do responsável 
técnico nas cozinhas de apoio, que deve implantar o MBP e o POP e aplicar normas já preconizadas pelas portarias vigentes.

Somente com a adequação das boas práticas, os food trucks analisados garantirão a credibilidade no serviço prestado e na qualidade dos alimentos, principalmente nos quesitos transporte, que deve proporcionar acondicionamento adequado que não provoque a multiplicação de patógenos e deterioração do alimento; estrutura física, cujo layout dos veículos e os equipamentos devem se adequar às diferentes etapas e finalização dos alimentos garantindo a organização dos utensílios, e controle de pragas, que por ser inviável a instalação de barreiras como medidas preventivas, o enfoque maior deve se dar por meio do controle efetivo por empresas capacitadas.

\section{CONCLUSÃO}

A análise das condições higienicossanitárias dos food trucks em relação à legislação vigente revelou condições higienicossanitárias insatisfatórias quanto aos itens que foram classificados como não conformes, principalmente nas etapas de produção, armazenamento, transporte e manipulação, que poderiam comprometer a qualidade e segurança do alimento vendido. Em contrapartida, observou-se que o descarte de resíduos era realizado de maneira correta e no que se refere à venda dos alimentos, encontrou-se uma particularidade positiva desse nicho de mercado, visto que os produtos só são finalizados sob demanda do consumidor, logo não necessitando de armazenamento. Portanto, considerando que as inconformidades nas diferentes etapas do processo produtivo, como manipulação, armazenamento e distribuição inadequada podem resultar no aparecimento de surtos de DTA, conclui-se que os food trucks devem aplicar as normas já preconizadas pela Portaria 2619, bem como adequarem os veículos e as cozinhas de apoio utilizadas.

\section{REFERÊNCIAS}

ABREU, E.S.; SPINELLI, M.G.N.; SOUZA PINTO, A.M. Gestão de Unidades de Alimentação e Nutrição: um modo de fazer. 5. ed. São Paulo: Editora Metha, 2013. $378 p$.

AGOSTINHO, T.M.S. Perfil do risco sanitário de alimentos comercializados em feiras especiais de Goiânia-GO. Tese (Mestrado em Nutrição e Saúde) - Faculdade de Nutrição da Universidade Federal de Goiás, 2013.

AMORIM, C. G. Intensidade do relacionamento interorganizacional no setor turístico de Curitiba-PR. Tese (Mestrado em Ciências Sociais Aplicadas) Universidade Federal do Paraná, Curitiba, 1999. 
AKUTSU, R.C. et al. Adequação das boas práticas de fabricação em serviços de alimentação. Rev. de Nutrição, v.18, n.13, p.419-427, 2005.

BOANOVA, A.B. Análise e interpretação de denúncias sobre alimentos como ferramenta de gestão no município de São Paulo. Tese (Doutorado - Saúde Pública) - Faculdade de Saúde Pública da Universidade de São Paulo, São Paulo, 2014.

BRASIL. Decreto no 55.085, de 6 de maio de 2014. Regulamenta a Lei no 15.947, de 26 de dezembro de 2013, que dispõe sobre as regras para comercialização de alimentos em vias e áreas públicas - comida de rua. Disponível em:

$<$ http://www3.prefeitura.sp.gov.br/cadlem/secretarias/negocios_juridicos/cadlem/integr a.asp?alt=07052014D\%20550850000 >. Acesso em: 15 mar. 2016.

BRASIL. Ministério da saúde - Doenças transmitidas por alimentos - Secretaria de Vigilância em Saúde, Brasília, 2007.

BRANDALIZE, P. C.; PERES, A. P.; PASSONI, C. M. S. Condições higienicossanitárias do comércio ambulante de alimentos, na feira de artesanato de Curitiba. Rev. Hig. Alim. v. 27, n. 216/217, p. 54-57, 2013.

BUSATO, M. A.; GRÄF, F. M.; ZAGONEL, L. C. Condições higiênicossanitárias do comércio ambulante de alimentos de Chapecó, SC. Rev. Hig. Alim., v. 28, n. 234/235, p. 68-72, 2014.

CARDOSO, L.; ARAÚJO, W. M. C. Perfil higiênico-sanitário de panificadoras do Distrito Federal. Rev. Hig. Alim., v.15, n.83, p.32-43, 2001.

CARDOSO, R. C. V.; SANTOS, S. M. C; SILVA, E. O. S. Comida de rua e intervenção: estratégias e propostas para o mundo em desenvolvimento. Ciência \& Saúde Coletiva, v.14, n.4, p.1215-1224, 2009.

CARDOSO, R.C.; SOUZA, E.V.A; SANTOS, P.Q. Unidades de alimentação e nutrição nos campi da Universidade Federal da Bahia: um estudo sob a perspectiva do alimento seguro. Rev. Nutrição, v.18, n.5, p.669-680, 2005.

CODEX ALIMENTARIUS. CAC/RCP 39 de 1993. Code of Hygienic Practice for Precooked and Cooked Foods in Mass Catering. Disponível em:

<http://www.codexalimentarius.net/web/standard_list.jsp>. Acesso em: 10 mai. 2016.

COSTA, J. N. P. et al. Condições higiênico-sanitárias e físico-estruturais da área de manipulação de carne in natura em minimercados de Recife (PE), Brasil. Arquivos do Instituto Biológico, v. 80, n. 3, p. 352-358, 2013.

FRANCO, A.C.R; UENO, B.M. Comércio Ambulante de Alimentos: Condições Higiênico-Sanitárias nos Pontos de Venda em Taubaté - SP. Cient. Ciênc. Biol. Saúde, v.12, n.4, p.9-13, 2010.

FREITAS, A. K. N. et al. Condições higiênico-sanitárias de gêneros alimentícios comercializados no Mercado Central São José em Teresina, PI. In: SIMPÓSIO DE SEGURANÇA ALIMENTAR: ALIMENTAÇÃO E SAÚDE, 5, 2015. Anais..., Porto Alegre, 2015. 
GENTA, T. M. S; MAURíCIO, A. A.; MATIOLI, G. Avaliação das Boas Práticas através de check-list aplicado em restaurantes self-service da região central de Maringá, Estado do Paraná. Acta Scientiarum. Health Sciences, v. 27, n. 2, p. 151-156, 2005.

GERMANO, M. I. S. et al. Manipuladores de alimentos: capacitar? É preciso. Regulamentar? Será preciso??? Rev. Hig. Alim., v.14, n. 78/79, p. 18-22, 2000.

HENRIQUES, P. et al. Atitudes de usuários de restaurante "self-service": um risco a mais para a contaminação alimentar. Cad. Saúde Colet., v.2, n. 3, p. 266-74, 2014.

IBGE. Instituto de Geografia e Estatística. Pesquisa de Orçamentos Familiares 2008-2009. 2010. Disponível em:

<http://www.ibge.gov.br/home/estatistica/populacao/condicaodevida/pof/2008_2009/P OFpublicacao.pdf>. Acesso em: 14 mar. 2016.

MARQUES, A. C.; VALENTE, T. B.; ROSA, C. S. Formação de toxinas durante o processamento de alimentos e as possíveis consequências para o organismo humano. Revista de Nutrição, v. 22, n. 2, p. 283-293, 2009.

NUNES, F.A. Implementação de boas práticas de fabricação (BPF) e do procedimento operacional padrão (POP) em cozinha industrial. Tese (Doutorado em Tecnologia em Alimentos) - Instituto Federal de Educação, Ciência e Tecnologia do Rio Grande, Bento Gonçalves, 2009.

OLIVEIRA, T.B.; MAITAN, V.R. Condições higiênico-sanitárias de ambulantes manipuladores de alimentos. Enciclopédia Biosfera, v.6, n.9, p.1-14, 2010.

PEREIRA, C. H. C. Avaliação das unidades de alimentação e nutrição da cidade de Franca visando a promoção de saúde. 84f. Dissertação (Mestrado em Promoção de Saúde) - Universidade de Franca, Franca - SP, 2006.

PIRAGINE, K. O. Aspectos Higiênicos e Sanitários do preparo da merenda escolar da rede estadual de ensino de Curitiba. 107p. Dissertação (Mestrado Tecnologia de Alimentos). Universidade Federal do Paraná, Curitiba, 2005.

POERNER, N. et al. Avaliação das condições higiênico-sanitárias em serviços de alimentação. Rev. Inst. Adolfo Lutz., v. 68, n. 3, p. 399-405, 2009.

PRAXEDES, P. C. G. Aspectos da qualidade higiênico-sanitária de alimentos consumidos e comercializados na comunidade São Remo, São Paulo, capital. 2003. Dissertação (Mestrado) - Faculdade de Medicina Veterinária e Zootecnia, Universidade de São Paulo, Piracicaba, 2003.

RONCANCIO, J.J.; QUICAZÁN, C.A.N.; CÁRDENAS, A.P. Iniciativas, ações e políticas sobre as vendas de alimentos na via pública. Cad. Saúde Coletiva, v.23, n.1, p.17-24, 2015.

ROOS, E.C. et al. Food Trucks guiando a inovação: um estudo sobre motivações e inovação no modelo de negócios no setor gastronômico de Porto Alegre. In: XVIII SEMINÁRIOS DE ADMINISTRAÇÃO, 18, 2015. Anais..., Porto Alegre: Universidade Federal do Rio Grande do Sul, 2015, p.1-17. 
SACCOL, A.L.F. Sistematização de ferramenta de apoio para boas práticas em serviços de alimentação. Dissertação (Mestrado) - Universidade Federal de Santa Maria, 2007.

SÃO PAULO. Secretaria Municipal da Saúde. Portaria SMS-G n²619 de 06 de dezembro de 2011. Regulamento de Boas Práticas e de Controle de condições sanitárias e técnicas das atividades relacionadas à importação, exportação, extração, produção, manipulação, beneficiamento, acondicionamento, transporte, armazenamento, distribuição, embalagem, reembalagem, fracionamento, comercialização e uso de alimentos, águas minerais e de fontes, bebidas, aditivos e embalagens para alimentos. Código Sanitário do Município de São Paulo. Publicada em DOC de 6/12/11, p. 23.

SEBRAE. Food Truck: modelo de negócio e sua regulamentação. [S.I.:S.n.], 2015, $47 p$.

SILVA JÚNIOR, E. A. Manual de Controle Higiênico-Sanitário em Serviços de Alimentação. 6. ed., São Paulo: Varela, 2007. 624 p.

SOARES, A.; MONTEIRO, M.; SCHAEFER, M. Avaliação do binômio tempo e temperatura em preparações quentes de um Restaurante Universitário. Rev. Hig. Alim., v. 23, n. 174/175, p. 36-41, 2009.

SOUZA, G.C. et al. Comida de rua: avaliação das condições higiênico-sanitárias de manipuladores de alimentos. Ciência \& Saúde Coletiva. v. 20, n. 8, p. 2329-2338, 2015.

TORASSI, M. Avaliação da temperatura de armazenamento de alimentos refrigerados em supermercados de criciúma - SC. Trabalho de Conclusão de Curso (Graduação em Farmácia) - Universidade do Extremo Sul Catarinense, 2009.

VARGAS, D.; UENO, M. Higiene na manipulação de lanches no comércio ambulante dos alimentos. Rev. Hig. Alim. v. 28, n.2 36/237, p. 38-43, 2014.

ZANDONADI, R. P. et al. Atitudes de risco do consumidor em restaurantes de autosserviço. Rev. Nutr., v. 20, n. 1, p. 19-26, 2007. 